\title{
Investigation of series-parallel connections of multi-module batteries for electrified vehicles
}

\author{
Federico Baronti, Roberto Di Rienzo, Nicola Papazafiropulos, Roberto Roncella, Roberto Saletti \\ Dipartimento di Ingegneria dell'Informazione \\ University of Pisa \\ Via Caruso 16, 56122 Pisa, Italy \\ r.saletti@iet.unipi.it
}

\begin{abstract}
Large-format Lithium-ion battery packs consist of the series and parallel connection of elemental cells, usually assembled into modules. The required voltage and capacity of the battery pack can be reached by various configurations of the elemental cells or modules. It is thus worth investigating if different configurations lead to different performance of the battery pack in presence of a mismatch in the cell characteristics. A simulation tool is developed in this work and applied to a battery pack consisting of standard $12 \mathrm{~V}$ modules connected with various serial/parallel topologies. The results show that battery configurations with modules directly connected in parallel and then assembled in series are more robust against variation of the cell capacity through the battery. Moreover, given the cells and the battery configuration, we show that changing the position of the cells has a significant impact on the usable capacity of the battery.
\end{abstract}

Keywords- Li-ion batteries; Cell parallel/serial connection; Battery-pack topology; Cell arrangement

\section{INTRODUCTION}

The penetration rate of Electric and Plug-in Hybrid Electric Vehicles (EVs/PHEVs) is increasing and it is expected that a large fraction of vehicles will be battery powered in the future [1]. The International Energy Agency (IEA) calls for 20 million EVs on the market by 2020 in order to reduce global Greenhouse Gas emissions (GHGs), but the current pace does not ensure that the announced policy targets can be met [2]. One of the key factors that is supporting the electrification of vehicle is the availability of batteries with chemistries that outperform the lead-acid batteries utilized in the first generation of EVs. In particular, the lithium-ion batteries, originally introduced for the low-power portable electronic devices, are now becoming the preferred solution also for medium and high-power applications [3]. Great research efforts are thus devoted to the development of new generation batteries and the associated control electronics, i.e., Battery Management Systems (BMS) [4], [5].

A recent study has underlined the importance of a standard battery module in order to achieve a massive electrification of off-road vehicles [6]. According to the study, it is possible to use a standard module of 4 series-connected lithium-ironphosphate (LFP) cells in order to build up the battery of many types of off-road vehicles. The standard module has a $12.8 \mathrm{~V}$ nominal voltage. Its implementation with three capacity values: 30,60 , and $100 \mathrm{Ah}$ is reported in [7].

A generic battery is obtained by connecting an appropriate number of standard modules in order to meet the voltage and capacity requirements given by the application. Modules can be parallel connected to obtain a higher capacity or serially connected to create battery strings with higher voltage. In turns, battery strings can be parallel connected to increase the capacity. In general, many different connection configurations can be devised to meet the required values of battery voltage and capacity. Evaluating the performance of each configuration is a crucial aspect of the design of the battery, especially in presence of a mismatch in the cell characteristics. Given the battery configuration, it is also interesting to investigate if the way the cells are placed in the battery has an impact on its performance.

\section{BACKGROUND}

Lithium-ion batteries are penetrating the market of the energy storage systems because of their excellent features in terms of specific and volumetric energy and power densities, charge/discharge efficiency, lifetime and performance. Thus, they are much more often used in EVs [8]. One single Lithium-ion (Li-ion) cell typically has a nominal voltage between $2.5 \mathrm{~V}$ and $4.2 \mathrm{~V}$ depending on the chemistry and a rather limited capacity, not sufficient for many applications. In order to meet the voltage and capacity required in automotive applications, tens to hundreds of cells are connected in series and parallel to build-up the battery pack. If the cells belonging to a pack are identical to each other, i.e., there is no mismatch among them, both the capacity and the voltage of the battery pack are proportional to those of the single cell, regardless of the connection topology of the battery. However, due to the inevitable differences in the manufacturing process and the different operating environment in which the cells may operate (e.g. the temperature), there are always some variations between the cell characteristics that cannot be eliminated. Unfortunately, cell variations can cause a significant degradation in capacity, life cycle and safety of the battery pack [9]-[11].

Once the required voltage, current and capacity are defined for the target application, it is easy to calculate the number of necessary cells. The battery voltage is set by the number of 
series-connected cells, whereas the battery capacity and the maximum battery current are given by the number of parallel connected cells [12]. For instance, if an application requires $240 \mathrm{Ah}$ capacity and $76.8 \mathrm{~V}$ nominal voltage and $3.2 \mathrm{~V} 60 \mathrm{Ah}$ cells are available, then 96 cells are required: 4 cells are placed in parallel to achieve the capacity and 24 cells in series for the voltage. Indeed, there are many possible connection topologies with which the array of $24 \times 4$ cells can be built.

The majority of researches on Li-ion battery packs is conducted by manufacturers under proprietary terms [13]. Several studies are available in the literature about the analysis, monitoring and testing of individual cells under a large variety of different conditions, whilst only a few papers are focused on the design, simulation and testing of complete battery packs [8]. As stated above, there is a great variety of possible connections, given the number of cells. Most of the studies on battery packs are focused on two main topologies [14]. The first approach consists in wiring the cells in parallel and then wiring the parallel-connected modules in series [15]. The cells are first wired in series in the second approach, and then the series-connected modules are wired in parallel [16]. Plett and Klein called these two approaches "parallel cell module" (PCM) and "series cell module" (SCM), respectively [12]. PCM and SCM were compared in their study and the influence of the cell mismatch on the global battery performance was investigated.

The result is that PCM batteries tend to smooth the differences among the cell capacities and resistances so that the pack remains usable even for large variations of these parameters. If one cell develops a leakage current, this can lead to a fault. If a cell develops a soft short-circuit fault, then all parallel-connected cells are subjected to the same fault as well. However, the pack is still operational with a lower terminal voltage. In SCM batteries, the strings placed in parallel self-balance each other when the pack is resting. However, the pack cannot balance itself quickly enough when the load is connected, as the load current is typically larger than the recirculation current between the strings. An open circuit fault on one cell electrically removes the whole string from the pack. A short circuit fault on one cell forces the cells of that string to a higher voltage, since the involved string must match the pack bus voltage set by the other strings in parallel.

The discharge characteristics of multi-cell batteries in different series-parallel connections with non-uniform cells have also been studied in [17]. The analysis reveals that in the series connection of non-uniform cells, the total capacity of the string is governed by the cell with the smallest capacity, whilst in the parallel connection, the total capacity is the sum of the individual cell capacity. It follows that for multi-cell batteries with serial and parallel connections of cells, the total capacity of SCM is smaller than the total capacity of PCM.

As to the best of our knowledge, there is no study which compares advantages and disadvantages of mixed approaches, i.e., topologies that combine PCM and SCM batteries, we carried out an investigation by simulating the behavior of multi-cell batteries, according to the methodology that will be described in the next section.

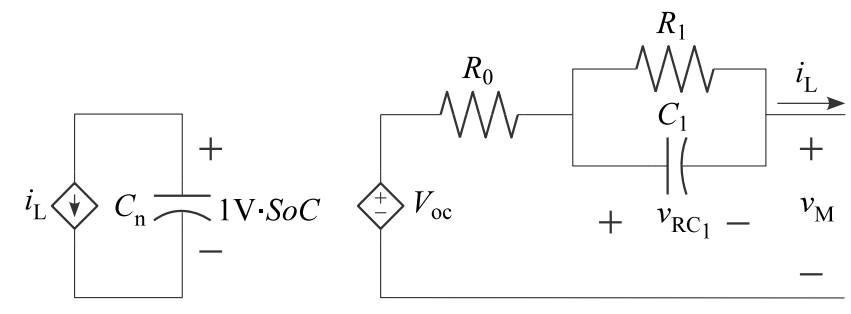

Fig. 1. Cell equivalent Randles circuit

\section{Methodology}

Battery packs are mainly modeled in the literature according to three approaches. The first approach is building a cell model and creating the pack model with the aggregation of series and parallel structures of cells. The second approach is scaling the cell model into a simplified battery pack model similar to the cell model. The third approach is building a battery pack model that captures the totality of the pack behavior [18].

The analysis described in this paper follows a hierarchical approach, so that the behavior of both the pack and the single cells are investigated. The base element is the module that consists of four series-connected cells. The single cell is modeled in its turn with the well-known first order Randles circuit shown in Fig. 1. A similar approach to model the cell in a battery pack is also adopted in [19] and [20]. The final level of the hierarchy is the battery pack that consists of 24 modules. The modules are connected to each other with different topologies that are investigated with simulations.

The Randles circuit of the cell and the various battery pack connections have been modeled and described with

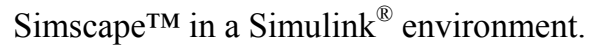

\section{A. Cell model}

A battery cell is usually modeled with an equivalent electric circuit or an electrochemical model [21]. They trade off the model simplicity with the better accuracy that a model deeply linked to the physical phenomena occurring inside the cell can give. Our choice was the equivalent electric circuit shown in Fig. 1, as it is a good compromise between accuracy and computational complexity.

The model consists of a capacitor $C_{n}$ that represents the battery capacity. Then, a non-linear voltage dependent voltage generator accounts for the relationship between the cell open circuit voltage (OCV) and the State-of-Charge (SoC). $R_{0}$ is the series resistance, which is the product of a constant term and a coefficient that is function of the SoC. The constant resistance $R_{1}$ and the constant capacitor $C_{1}$ account for the relaxation phenomena that occur in Li-ion cells. The cell model is also provided with a Boolean output variable that is asserted when the cell is outside the safety voltage limits suggested by the cell manufacturer. The variable operates as a cell alarm useful to identify which cell of the pack is exceeding the safe zone.

\section{B. Battery modelling}

The battery module presented in [4] is composed by 4 series-connected cells and a BMS with a circular bus for 


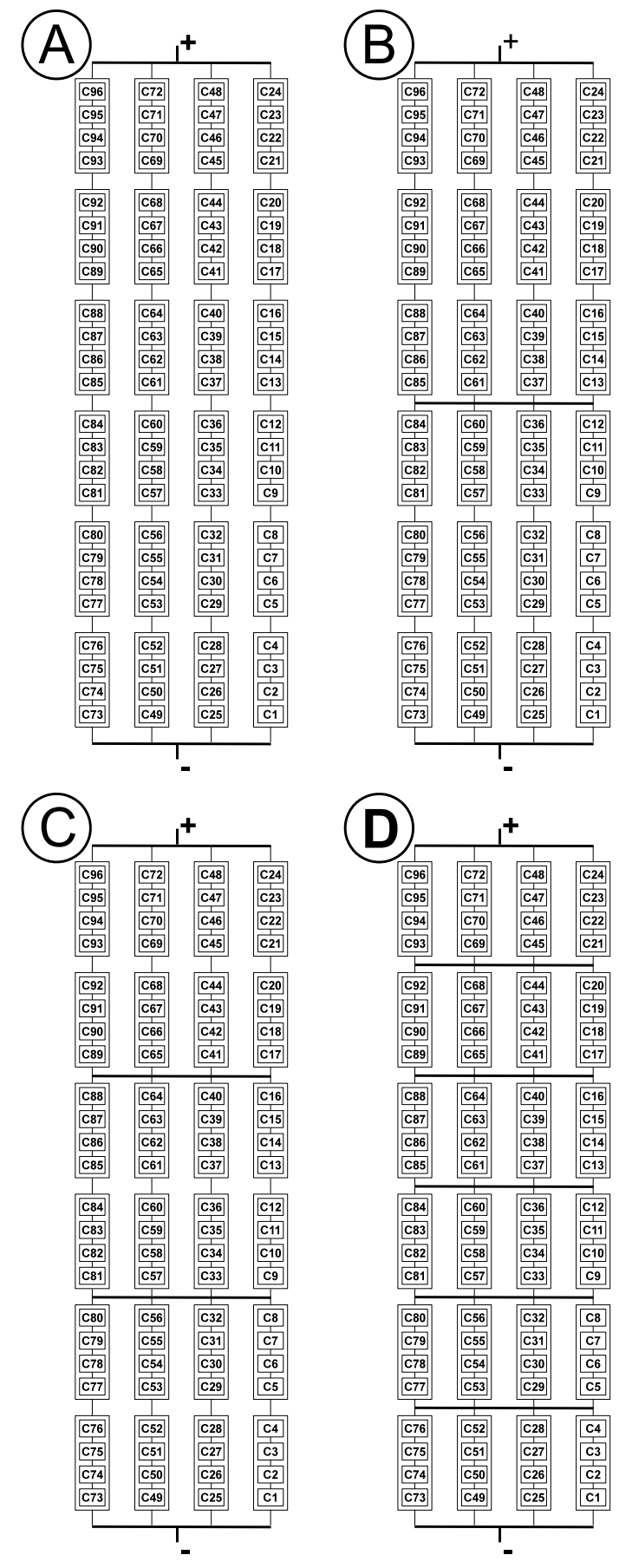

Fig. 2. Studied topologies

balancing the cell charges. As far as the analysis described in this paper is concerned, the BMS operations that can possibly be carried out in each module are omitted, as the focus of the paper is just exploring the connection topology influence on the battery pack performance. Therefore, the internal balancing in the four-cell module is not considered, as if the module BMS was not operative. Each module is then connected with different topologies to build up the battery pack.

\section{Case study}

As mentioned before, the standard module is the basic building block of the battery pack. The case study investigated is a battery pack with $240 \mathrm{Ah}$ capacity and $76.8 \mathrm{~V}$ nominal voltage. The module nominal voltage is $12.8 \mathrm{~V}$ and the capacity is $60 \mathrm{Ah}$. Thus, 24 modules are required. They are organized in an array with 4 units in parallel (240 Ah) and 6 units in series $(76.8 \mathrm{~V})$. Several connection topologies are possible inside the array. We chose to study the regular topologies showed in Fig. 2 in the preliminary investigation attempts described in this paper. The configurations $\mathrm{A}$ and $\mathrm{D}$ resemble the SCM and PCM connections referenced above, whereas the configurations $\mathrm{B}$ and $\mathrm{C}$ are hybridizations between $\mathrm{A}$ and $\mathrm{D}$, being the parallel groups 2 and 4 respectively.

All the parameters of the cell model are configurable. They can individually be assigned for each cell by means of a Matlab script. This is the way by which the cell mismatch is taken into account. So, varying the cell parameters according to a statistical distribution allow us to have battery packs with different topologies made of non-uniform cells.

It is important to discuss the way in which the cell mismatch is implemented in the battery model. If we consider the variations in the fabrication process of the battery cell the cell capacity can be represented as a random variable with a reasonably normal distribution around a mean value. As a lower series resistance corresponds to a larger capacity, the assumption we made is to consider constant the product between the cell series resistance and capacity [22].

\section{Simulations}

This section discusses the results obtained by simulating the above described battery pack configurations with some distributions of the cell mismatches.

\section{A. Capacity of different topologies}

The simulations start with the SoC of each cell set at $100 \%$. Then the battery is discharged at $1 \mathrm{C}$ rate $(240 \mathrm{~A})$ until a cell voltage exceeds the safe area, condition that is signaled by the cell alarm Boolean variable.

First simulations aim at investigating the dependence of the full battery capacity on the connection topology of the cells when some variations in the cell parameters are introduced. Before doing this, we verified that all the four topology provide a total battery capacity equal to four times that of a single cell when all the cells are perfectly matched.

To account for cell mismatch, the capacity of each cell is randomly generated with a Gaussian distribution having a mean value of $60 \mathrm{Ah}$ (the nominal capacity of the cells) and three different values of the standard deviation: $2.5 \%, 5 \%$ and $10 \%$. These 3 values are representative of the capacity differences between the cells of the same pack, at the beginning of their life and during their ageing, which tends to increase cell differences [23]. 

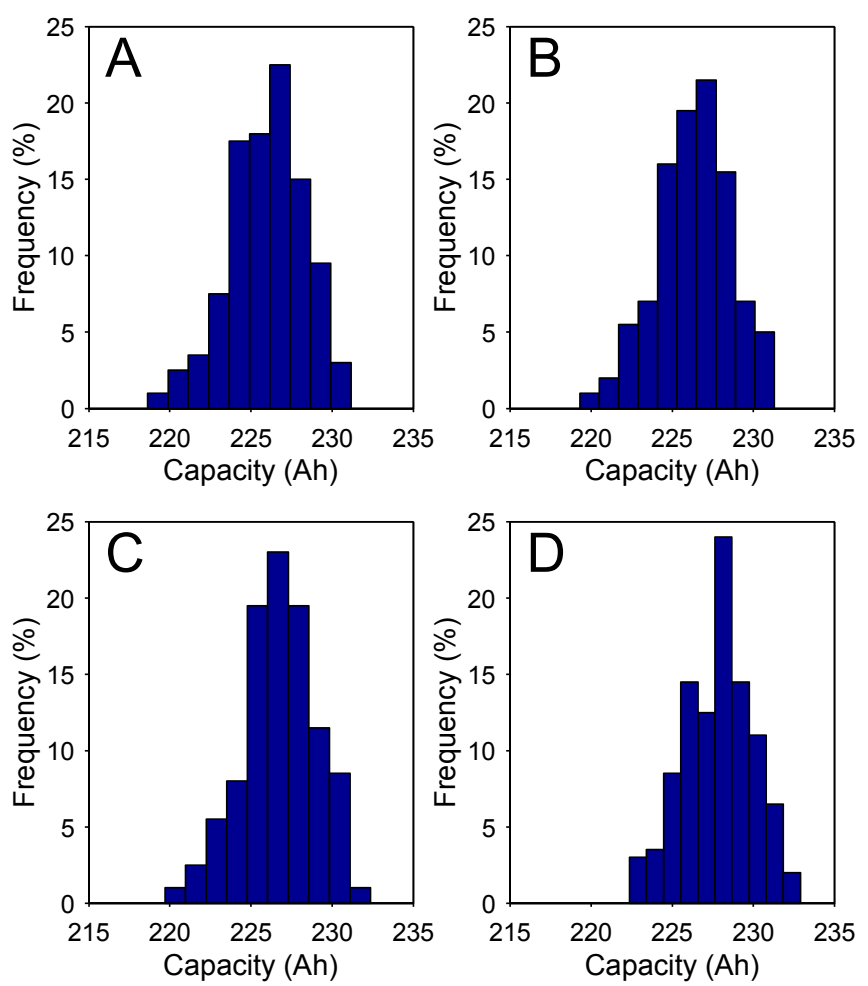

Fig. 3. Battery capacities with $2.5 \%$ standard deviation of the cell capacity
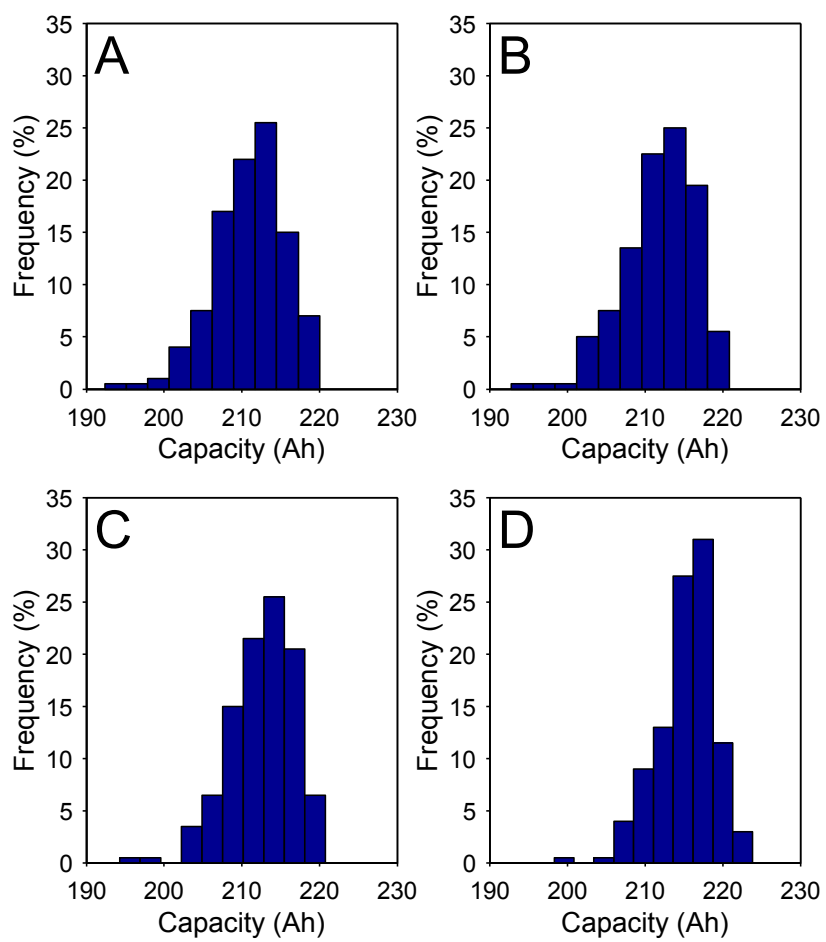

Fig. 4. Battery capacities with $5 \%$ standard deviation of the cell capacity

We performed 200 simulations for each value of the standard deviation, evaluating the behavior of the four previously described architectures for each randomly generated battery. Fig. 3 shows the histogram of the battery pack capacity when the capacity cell mismatch has a standard
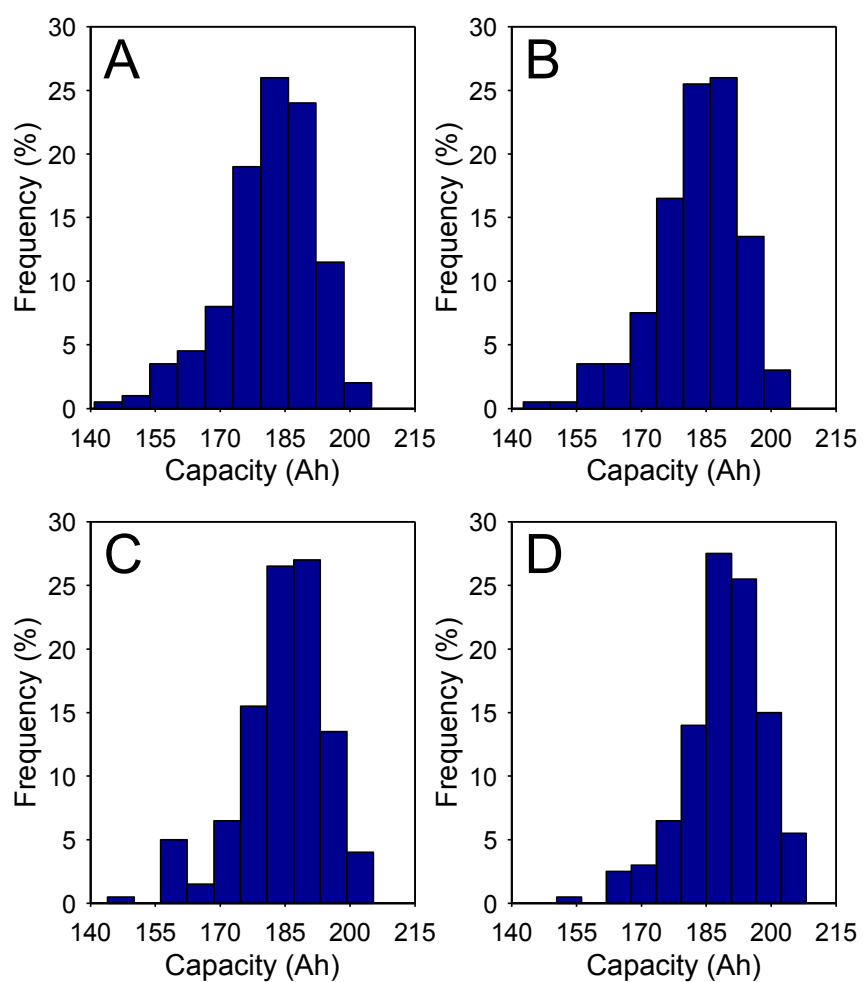

Fig. 5. Battery capacities with $10 \%$ standard deviation of the cell capacity

deviation of $2.5 \%$. The height of each bin indicates the relative frequency of occurrences, i.e. the number of occurrences of each bin divided by 200 . It is worth noting that the usable capacity of the pack is around $226 \mathrm{Ah}$ and it is strongly reduced with respect to the nominal capacity of $240 \mathrm{Ah}$, even with a rather small mismatch variance. Fig. 4 and Fig. 5 show the histograms when the standard deviation of the random distribution is $5 \%$ and $10 \%$, respectively. The results show how the global battery performance is strongly degraded by the capacity mismatch. In the $10 \%$ standard deviation case, the available capacity is on average reduced to a value ranging from $76 \%$ (for topology A) to $79 \%$ (for topology D) of the 240 Ah theoretical total capacity.

If the various connection configurations are compared to each other, the results confirm the findings reported in the literature [12], as configuration $\mathrm{D}$ statistically provides a higher capacity than configuration $\mathrm{A}$. We add the results that configurations $\mathrm{C}$ and $\mathrm{B}$ provide intermediate capacity values on average. However, this trend is very limited for the lowest value of the variance and significantly emerges with larger capacity variance: the higher the variance, the higher the capacity difference between the configurations. Another interesting result shown by the simulations is that the histograms of the total capacity for the various configurations seem to be more spread from D to A. Let us calculate and report in Table $\mathrm{I}$, the average value $\eta$ and the standard deviation $\sigma$ of the total battery capacity, for each configuration in the three cases. We notice that configuration D provides more capacity with less statistical spreading. This occurs for all the three cases investigated. 


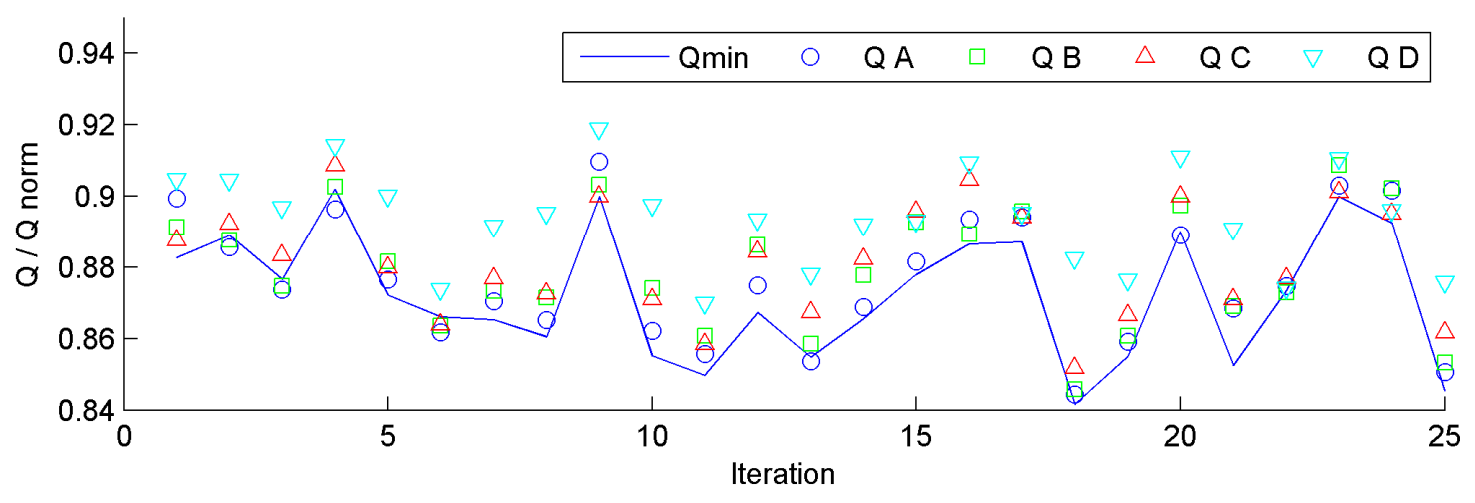

Fig. 6. First 25 results of the simulation at $2.5 \%$ standard deviation

Fig. 6 shows the simulation results of the first 25 random extractions in the case of $2.5 \%$ cell capacity standard deviation. The battery capacity of each configuration is compared to the minimum cell capacity found in that particular extraction. The battery capacity is normalized to $240 \mathrm{Ah}$ (nominal battery capacity) whilst the minimum cell capacity is normalized to $60 \mathrm{Ah}$ (nominal cell capacity). It is interesting to note that there are cases in which the normalized capacity of the battery is lower than the minimum cell capacity of the pack. This apparently weird result can easily be explained by considering that the parallel connection selfbalances the different open circuit voltages of the involved elements by letting a circulation current flow between the strings. If the minimum capacity cell belongs to a string that is not the least in capacity and thus provides charge to the other strings, it happens that part of the charge of that minimum capacity cell does not go to the load. This means that the battery provides to the load a total capacity that is even lower than the minimum capacity cell.

\section{B. Effects of cell arrangement in the same topology}

The above considerations suggest that the performance of a battery also depends on the arrangement of its cells. Since configuration A of Fig. 2 showed a higher sensitivity of the total capacity on the cell mismatch, we decided to choose this topology to investigate how a battery-pack is affected by different arrangements of the same cells. The capacity distribution of the cells used in this analysis is shown in Fig. 7.

Given the topology of a battery-pack, its cells can still be arranged in a large number of different ways. Some of them are however equivalent, as no variation in the battery performance can be expected when changing the order of the cells in a string or switching one string with another. In

TABLE I. TOTAL BATTERY CAPACITY

\begin{tabular}{|l|c|c|c|c|c|c|}
\hline \multirow{2}{*}{ Conf. } & \multicolumn{2}{|c|}{$\mathbf{2 . 5 \%}$} & \multicolumn{2}{c|}{$\mathbf{5 \%}$} & \multicolumn{2}{c|}{$\mathbf{1 0 \%}$} \\
\cline { 2 - 7 } & $\boldsymbol{\eta}$ (Ah) & $\boldsymbol{\sigma}$ & $\boldsymbol{\eta}(\mathbf{A h})$ & $\boldsymbol{\Sigma}$ & $\boldsymbol{\eta}(\mathbf{A h})$ & $\boldsymbol{\sigma}$ \\
\hline $\mathrm{A}$ & 225.97 & $2.246 \%$ & 211.11 & $8.681 \%$ & 181.61 & $45.492 \%$ \\
\hline $\mathrm{B}$ & 226.35 & $2.106 \%$ & 211.83 & $8.597 \%$ & 182.87 & $42.403 \%$ \\
\hline $\mathrm{C}$ & 226.72 & $2.210 \%$ & 212.63 & $7.311 \%$ & 184.52 & $43.169 \%$ \\
\hline $\mathrm{D}$ & 227.85 & $1.867 \%$ & 215.28 & $5.866 \%$ & 189.13 & $34.394 \%$ \\
\hline
\end{tabular}

mathematical terms, given a parallel battery of $p$ strings of $s$ cells each, the $p \times s$ cells can be arranged in $n$ non-equivalent ways, where $n$ is given by the following relationship.

$$
n=\frac{(p \cdot s) !}{p !(s !)^{p}}
$$

For our case-study, $p=4$ and $s=24$, thus $n$ is in the order of $10^{54}$. Consequently, simulating all the possible cases is unfeasible from a computational point of view. We therefore decided to simulate 100 random arrangements of the same cells. The results of these simulations are reported in Fig. 8, together with 6 cases of interest, labeled with letters from $a$ to $f$. In order to describe the cases of interest, let us sort the cells by their capacity in ascending order. Be $\mathrm{S}_{1}, \mathrm{~S}_{2}, \mathrm{~S}_{3}, \mathrm{~S}_{4}$ the strings, $\mathrm{C}_{1}, \mathrm{C}_{2}, \ldots, \mathrm{C}_{96}$ the cells and $\mathrm{Q}_{1}, \mathrm{Q}_{2}, \ldots, \mathrm{Q}_{96}$ their capacity, then:

$$
\mathrm{Q}_{1} \leq \mathrm{Q}_{2} \leq \ldots \leq \mathrm{Q}_{96}
$$

The cases of interest are chosen to investigate particular arrangements of which we foresee the performance. The expected "best" case (case $a$ ), is obtained by placing the 24 lowest capacity cells in the first string, the cells from 25 to 48 in the second string, the cells from 49 to 72 in the third string

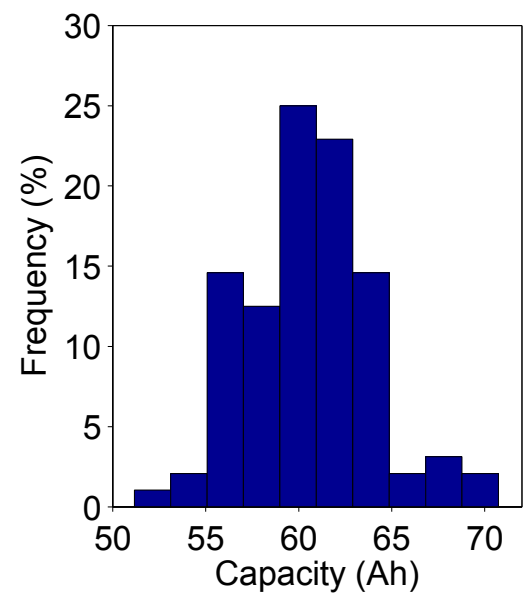

Fig. 7. Cell capacity distribution in the studied battery-pack 


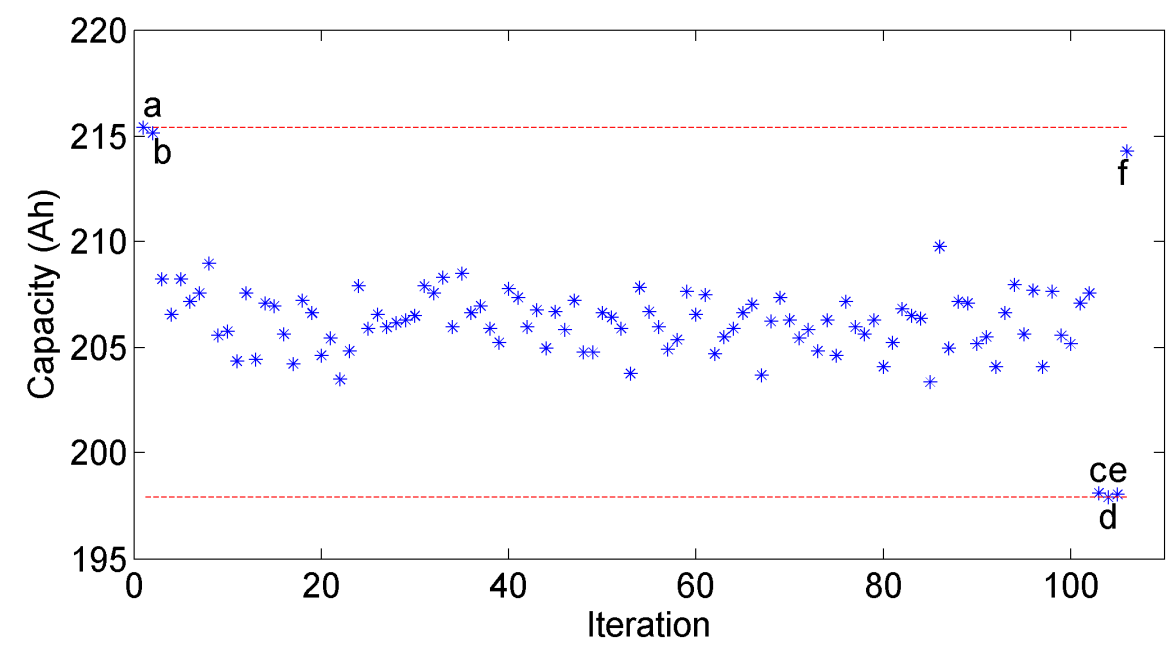

Fig. 8. Battery capacities for configurations $a-f$ and 100 random permutations of the cells

and the last 24 cells in the fourth string. With a compact notation, the battery $B_{a}$ can be represented as:

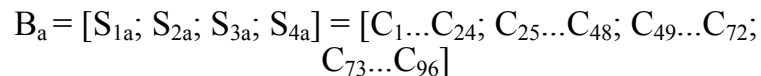

where $\mathrm{S}_{i}$ with $i=1 \ldots 4$ is a string of 24 cells. The symbol ";" indicates that the strings are connected in parallel.

Case $b$ is similar to case $a$ except that strings $\mathrm{S}_{2 b}-\mathrm{S}_{4 b}$ are obtained by randomly selecting cells $\mathrm{C}_{25}-\mathrm{C}_{96}\left(\mathrm{~B}_{\mathrm{b}}=\left[\mathrm{S}_{1 \mathrm{a}} ; \mathrm{S}_{2 \mathrm{~b}}\right.\right.$; $\left.\left.\mathrm{S}_{3 b} ; \mathrm{S}_{4 \mathrm{~b}}\right]\right)$. The purpose of this case is to analyze if the batterypack performance is affected by the way in which the other three strings are formed.

Then we consider 3 configurations that are expected to have the worst behaviors. For the case $c$, we kept the same structure as in $a$, but we exchanged the cell $\mathrm{C}_{1}$ with the cell $\mathrm{C}_{73}$ :

$$
\begin{aligned}
\mathrm{B}_{\mathrm{c}}=\left[\mathrm{S}_{1 \mathrm{c}} ; \mathrm{S}_{2 \mathrm{c}} ; \mathrm{S}_{3 \mathrm{c}} ; \mathrm{S}_{4 \mathrm{c}}\right] & =\left[\mathrm{C}_{73} \mathrm{C}_{2} \ldots \mathrm{C}_{24} ; \mathrm{C}_{25} \ldots \mathrm{C}_{48} ; \mathrm{C}_{49} \ldots \mathrm{C}_{72} ;\right. \\
& \left.\mathrm{C}_{1} \mathrm{C}_{74} \ldots \mathrm{C}_{96}\right]
\end{aligned}
$$

Configuration $d$ is obtained from $c$, keeping the fourth string and placing the other cells randomly $\left(\mathrm{B}_{\mathrm{d}}=\left[\mathrm{S}_{1 \mathrm{~d}} ; \mathrm{S}_{2 \mathrm{~d}} ; \mathrm{S}_{3 \mathrm{~d}}\right.\right.$; $\left.\mathrm{S}_{4 \mathrm{c}}\right]$ ). The configuration $e$ is obtained from $a$, placing the 3 cells with the lowest capacity in string 4,3 and 2 , respectively.

$$
\mathrm{B}_{\mathrm{e}}=\left[\mathrm{S}_{1 \mathrm{e}} ; \mathrm{S}_{2 \mathrm{e}} ; \mathrm{S}_{3 \mathrm{e}} ; \mathrm{S}_{4 \mathrm{e}}\right]=\left[\mathrm{C}_{4} \ldots \mathrm{C}_{25} \mathrm{C}_{49} \mathrm{C}_{73} ; \mathrm{C}_{3} \mathrm{C}_{26} \ldots \mathrm{C}_{48} ;\right.
$$

The simulations results of cases a-e shown in Fig. 8 confirm our predictions. In particular, the best cases $a$ and $b$ provide a capacity around $9 \%$ higher than the capacity of the worst cases $c-e$. Finally, we note that in cases $a-e$ the cell of the battery that firstly reaches the cut-off voltage is the worst cell, as it might be expected. However, if we built the case $f$ from configuration $b$ by exchanging the cell $\mathrm{C}_{73}$ with the cell $\mathrm{C}_{5}$,

$$
\mathrm{B}_{\mathrm{f}}=\left[\mathrm{S}_{1 \mathrm{f}} ; \mathrm{S}_{2 \mathrm{f}} ; \mathrm{S}_{3 \mathrm{f}} ; \mathrm{S}_{44}\right]=\left[\mathrm{C}_{1} \ldots \mathrm{C}_{4} \mathrm{C}_{6} \ldots \mathrm{C}_{24} \mathrm{C}_{73} ; \mathrm{C}_{25} \ldots \mathrm{C}_{48} ;\right.
$$

we find out that cell $\mathrm{C}_{5}$ is the first cell to reach cut-off voltage, even if its capacity is higher than the minimum cell capacity. The result is reasonable as the string 4 provides charge also to the other strings because of the parallel connection. Therefore, its discharging current is higher than that of the other strings. This can lead its weaker cell to reach the cutoff voltage before the minimum capacity cell. These preliminary simulation results show that the arrangement of inhomogeneous cells in a parallel battery pack may lead to large differences in the total capacity of the battery. Moreover, the particular cases investigated seem to be the bounds within which a random cell arrangement falls.

\section{CONCLUSIONS}

This paper describes the results of the investigation carried out on Lithium-ion battery packs consisting of standard $12.8 \mathrm{~V}$ modules connected according to different series and parallel topologies to achieve the capacity and voltage required by the application. The battery packs are modeled with a hierarchical model of elemental cells first assembled in modules of 4 series connected cells. The modules are then connected in various parallel/series configurations and their behavior is simulated finding the total capacity provided to the load when a mismatch in the cell parameters is introduced. A statistical distribution of the cell capacity with Gaussian density and different variance values is applied. The results show that the capacity mismatch from cell to cell may significantly reduce the pack capacity and that the series connection of parallel modules of cells provides the best connection topology, as it maximizes the capacity of the pack and reduces the statistical dispersion of the values. Given a topology, the effect of the variation of the cell arrangement is investigated too. The results show that arranging the cells in different ways can produce a significant variation in the pack capacity. Therefore the arrangement of the cells inside the battery-pack seems to be a crucial point, especially in applications with 
inhomogeneous cells as in battery second-life applications. Other significant results are that the capacity of the pack can be lower than the minimum cell capacity and that the cell of the pack which first reaches the discharge cut-off voltage may not be the cell with minimum capacity.

\section{REFERENCES}

[1] R. Faria, P. Marques, R. Garcia, P. Moura, F. Freire, J. Delgado, A. T. de Almeida, "Primary and secondary use of electric mobility batteries from a life cycle perspective", Journal of Power Sources 262 (2014) $169-177$

[2] M. Catenacci, E. Verdolini, V. Bosetti, G. Fiorese, "Going electric: Expert survey on the future of battery technologies for electric vehicles", Energy Policy 61 (2013) 403-413

[3] M. S. Whittingham, "History, Evolution, and Future Status of Energy Storage," Proc. IEEE 100 (2012) 1518-1534

[4] L. Lu, X. Han, J. Li, J. Hua, and M. Ouyang, "A review on the key issues for lithium-ion battery management in electric vehicles," Journal of Power Sources 226 (2013) 272-288

[5] H. Rahimi-Eichi, U. Ojha, F. Baronti, and M.-Y. Chow, "Battery Management System: An Overview of Its Application in the Smart Grid and Electric Vehicles," IEEE Industrial Electronic Magazine 7 (2013) 4 16

[6] F. Vellucci, G. Pede, M. Ceraolo, T. Huria, "Electrification of off-road vehicles: examining the feasibility for the Italian market", in EVS26 International Battery, Hybrid and Fuel Cell Electric Vehicle Symposium (2012) 1-17

[7] F. Baronti, G. Fantechi, R. Roncella, R. Saletti, G. Pede, F. Vellucci, "Design of the Battery Management System of $\mathrm{LiFePO}_{4}$ Batteries for Electric Off-Road Vehicles", in Proc. of the 2013 IEEE International Symposium on Industrial Electronics (2013) 1-6

[8] G. J. Offer, V. Yufit, D. A. Howey, B. Wu, N. P. Brandon, "Module design and fault diagnosis in electric vehicle batteries", Journal of Power Sources 206 (2012) 383-392

[9] Sebastian Paul, Christian Diegelmann, Herbert Kabza, Werner Tillmetz, "Analysis of ageing inhomogeneities in lithium-ion battery systems", Journal of Power Sources 239 (2013) 642-650

[10] Radu Gogoana, Matthew B. Pinson, Martin Z. Bazant, Sanjay E. Sarma, "Internal resistance matching for parallel-connected lithium-ion cells and impacts on battery pack cycle life", Journal of Power Sources 247 (2014) 332-338
[11] Y. Zheng, M. Ouyang, L. Lu, J. Li, X. Han, L. Xu, "On-line equalization for lithium-ion battery packs based on charging cell voltages: Part 1. Equalization based on remaining charging capacity estimation", Journal of Power Sources 247 (2014) 676-686

[12] G. L. Plett and M. J. Klein, "Simulating Battery Packs Comprising Parallel Cell Modules and Series Cell Modules," in CD-ROM Proc. 24th Electric Vehicle Symposium (EVS24), Stavanger, Norway (2009) 1-17

[13] N. Lotfi, P. Fajri, S. Novosad, J. Savage, R.G. Landers, M. Ferdowsi, 2013, "Development of an Experimental Testbed for Research in Li-Ion Battery Management Systems," Energies 6 (2013) 5231-5258

[14] Liang Zhong, Chenbin Zhang, Yao He, Zonghai Chen, "A method for the estimation of the battery pack state of charge based on in-pack cells uniformity analysis", Applied Energy 113 (2014) 558-564

[15] X. Gong, R. Xiong, C. C. Mi, "Study of the characteristics of battery packs in electric vehicles with parallel-connected lithium-ion battery cells", in Proc. of IEEE Applied Power Electronics Conference and Exposition - APEC (2014), 3218-3224

[16] R. Spurrett, C. Thwaite, A. Holland, D. Lizius, G. Dudley, A. Wilson "Modelling of highly-parallel lithium-ion batteries," in Proc. of the Sixth European Space Power Conference, A. Wilson Ed., 502 (2002) 685-691

[17] S. Miyatake, Y. Susuki, T. Hikihara, S. Itoh, K. Tanaka, "Discharge characteristics of multicell lithium-ion battery with nonuniform cells", Journal of Power Sources 241 (2013) 736-743

[18] J. Li, M. S. Mazzola, "Accurate battery pack modeling for automotive applications", Journal of Power Sources 237 (2013) 215-228

[19] M. Dubarry, N. Vuillaume, B. Y. Liaw, "From single cell model to battery pack simulation for Li-ion batteries" Journal of Power Sources 186 (2009) 500-507

[20] J. Kim, J. Shin, C. Chun, B.H. Cho, "Stable Configuration of a Li-Ion Series Battery Pack Based on a Screening Process for Improved Voltage/SOC Balancing", IEEE Transactions on Power Electronics 27 (2012) 411-424.

[21] A. Seaman, T.-S. Dao, J. McPhee, "A survey of mathematics-based equivalent-circuit and electrochemical battery models for hybrid and electric vehicle simulation", Journal of Power Sources 256 (2014) 410423

[22] G. Pistoia, "Lithium-Ion Batteries: Advances and Applications," Elsevier, 2014

[23] Thorsten Baumhöfer, Manuel Brühl, Susanne Rothgang, Dirk Uwe Sauer, "Production caused variation in capacity aging trend and correlation to initial cell performance", Journal of Power Sources 247 (2014) 332-338 